\title{
Metodologia de didatização de medições elétricas em sistemas de injeção eletrônica automotiva
}

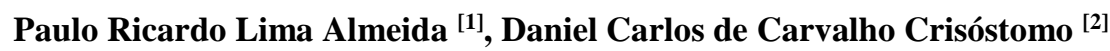 \\ [1] Universidade Federal Rural do Semi-árido; pauloricardo021@ gmail.com \\ ${ }^{[2]}$ Universidade Federal Rural do Semi-árido; daniel.crisostomo@unp.br \\ Recebido: 21/06/2019; \\ Aceito: $12 / 08 / 2019$; \\ Publicado: 07/10/2019.
}

Resumo: A frota de veículos automotores trafegando nas estradas brasileiras vem crescendo continuamente. Junto deles, a necessidade de manutenção constante e conhecimentos básicos sobre parâmetros e diagnósticos de possíveis falhas que o sistema eletrônico do carro possa vir a apresentar tornam-se primordiais para evitar diversos tipos de transtornos na hora da realização da manutenção. Este trabalho objetiva informar aos proprietários de veículos automotores a respeito da realização de possíveis diagnósticos em diversos componentes do sistema de injeção eletrônica bem como o funcionamento do motor a combustão interna que os equipam, de forma clara e sequenciada para melhor compreensão da metodologia aplicada, para que os mesmos não sejam pegos de surpresa com orçamentos de serviço elevados ou até mesmo enganados com substituição de peças de forma desnecessária na hora que levarem seus veículos a oficina. Para isso utilizouse o multímetro digital, de fácil aquisição e baixo custo, onde foram feitas medições simples, porém de alta precisão. Foram obtidos resultados claros e precisos sendo possível assim identificar se tais componentes estavam ou não dentro dos parâmetros de funcionamento, de acordo com os valores exigidos para aquele veículo.

Palavras-chave: injeção eletrônica; multímetro; motor; diagnósticos.

\section{INTRODUÇÃO}

A

Os automóveis estão presentes no Brasil desde o início do século XX onde eram extremamente caros, símbolos de luxo e ostentação. Somente em 1970 com a criação de carros de menor motorização, 1000 cilindradas, a classe média conseguira entrar nesse patamar social e por volta de 1990 com o aumento da renda do brasileiro e a estabilização monetária que a popularização dos automóveis tornava realidade. Desde então, devido a facilidades financeiras para a aquisição bem como a defasada mobilidade urbana brasileira e também a cultura do status social, o aumento da frota de veículos tem aumentado diariamente [1].

Tendo em vista a crescente frota de veículos automotores no Brasil e a grande dificuldade de seus proprietários em compreender seu funcionamento básico relativo ao sistema de injeção eletrônica que os equipam, faz-se necessário a disseminação do conhecimento relativo a noções básicas de funcionamento e atuação de seus componentes bem como testes básicos, porém de alta confiabilidade, de modo que todos possam compreender e realizar diagnósticos precisos em seus próprios automóveis..

\section{MOTORES CICLO OTTO}

\subsection{História}

Em meados do século XVII o homem iniciava a tentativa para construir um mecanismo para fornecer força de maneira automática para complementar e até mesmo substituir a força animal e que pudesse levá-lo a maiores distâncias e velocidades. Na década de 60 do século seguinte surge a ideia de construir uma máquina que utilizasse benzeno como combustível mas foi apenas em 1866 o alemão Nikolaus August Otto tornou concretizou essa ideia. Otto era inventor e engenheiro quando criou o primeiro motor a combustão interna de 4 
tempos, sendo eles admissão, compressão, explosão e exaustão, que recebera seu nome em sua homenagem. Em relação as tecnologias existentes na época, a invenção de Otto demonstrou inúmeras vantagens como baixo peso em relação ao motor a vapor utilizado até então, já que havia a necessidade de grandes reservatórios de água, além de carvão ou lenha para ser queimado para aquecer a água [2].

\subsection{Funcionamento}

O motor de combustão interna consiste de componentes mecânicos e elétricos com a finalidade de produzir trabalho rotativo através de ciclos termodinâmicos, em outras palavras, pela força da expansão resultante da queima da mistura ar combustível no interior da câmara de combustão [3].

Como partes principais tem-se:

- Árvore de manivelas (virabrequim): dispositivo mecânico responsável por transformar o movimento linear das bielas em movimento rotativo através manivelas, estas dispostas em um ângulo de $180^{\circ}$ nos motores quatro cilindros [3];

- Bielas: componente construído em aço liga que transmite o movimento dos pistões à árvore de manivelas [3];

- Pistões: fabricados em liga de alumínio e de forma cilíndrica tem como função receber a força da expansão dos gases da explosão na câmara de combustão. Estes possuem anéis metálicos chamados anéis de segmento que servem para promover a vedação entre o pistão e o bloco o motor [3];

- Cabeçote: fabricando em liga de alumínio leve, é parafusado em cima do bloco do motor selando a câmara de combustão. No mesmo está contido as válvulas de admissão e escape, comandos de válvulas e velas de ignição [3];

- Válvulas: hastes que possuem extremidades achatadas em forma de disco que se assentam perfeitamente na face inferior do cabeçote. Elas promovem através de movimentos lineares a abertura e fechamento deixando a mistura de ar e combustível entrar, no caso da admissão, ou os resíduos da combustão saírem, no caso do escape [3];

- Comando de válvulas: ligado à árvore de manivelas por uma correia, ele é responsável por abrir e fechar as válvulas no tempo certo promovendo o excelente funcionamento do motor [3];

- Velas de ignição: elemento do sistema responsável por causar a centelha na câmara de combustão [3].

Para que o motor funcione de forma correta existem alguns parâmetros que devem ser observados como por exemplo a sincronia: a parte superior do motor deve estar sincronizada com a parte inferior para que não haja mal funcionamento ou até mesmo a quebra de componentes. Temos também o chamado ponto de ignição do motor: é o momento certo da centelha da vela dentro da câmara de combustão. Esse ponto de ignição nos carros atuais é feito eletronicamente mas nos carros mais antigos é feito de forma manual [3].

\section{SISTEMA DE INJEÇÃO ELETRÔNICA}

\subsection{Estrutura Geral}

Inventada em 1912 pela Robert Bosch a injeção eletrônica somente apareceu no Brasil em 1989 nos veículos Gol da Volkswagen, porém, hoje cobre todos os carros produzidos. O sistema é composto basicamente por sensores, atuadores e a ECU (Eletronic Central Unit) responsável por gerenciar todo o funcionamento do carro. Os sensores são responsáveis por enviar a ECU informações em tempo real do que estar acontecendo com o motor antes, durante e após seu funcionamento. Já os atuadores, como o próprio nome já diz, irão atuar de forma mecânica as funções enviadas pela ECU [4].

\section{2. $E C U$}

Principal componente da injeção eletrônica, a ECU, como mostra a Figura 1.1, é quem comanda todos os parâmetros eletrônicos monitorando e controlando o funcionamento do sistema. Para isso, ele trabalha em conjuntos com uma série de sensores e atuadores que receberão e atuarão, respectivamente, em diversas partes do motor para que haja o perfeito funcionamento do sistema. O tempo de injeção, a variação do ângulo de avanço de 
ignição e acionamento do eletro ventilador do sistema de arrefecimento são exemplos de funções da mesma. A ECU possui uma memória interna onde registra e grava erros nos parâmetros de funcionamento quando eles ocorrem e indicam ao motorista que existe tal anomalia existe no sistema, e que precisam ser verificadas, através da lâmpada de anomalia do sistema de injeção, mostrada na Figura 1.2 [5].

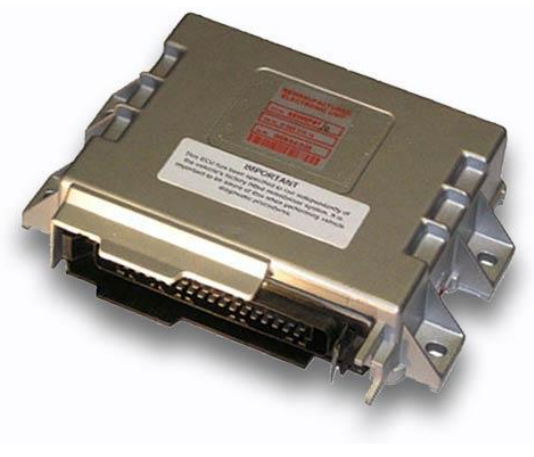

FIGURA 1.1. ECU (Autokey.ie, 2018).

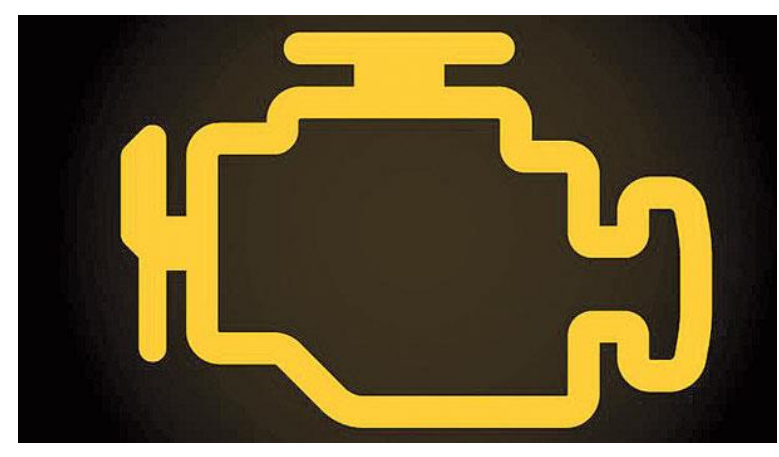

FIGURA 1.2. Luz de Anomalia do Sistema de Injeção (Oficinabrasil.com, 2018).

\subsection{Atuadores}

\subsubsection{Atuador de Marcha Lenta}

Através desse atuador também conhecido como motor de passo, mostrado na Figura 2, a ECU faz o controle da rotação do motor quando o mesmo encontra-se em marcha lenta, ele está fixado no corpo de borboleta, e permite uma variação na passagem de ar enquanto a borboleta se encontra fechada, momento esse quando o pedal do acelerador não é acionado, controlando a rotação programada pela ECU [5].

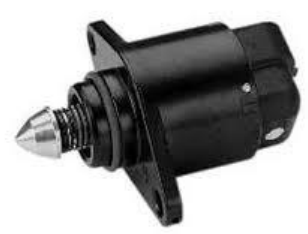

FIGURA 2. Atuador de Marcha Lenta (Canaldapeça.com, 2018).

\subsubsection{Válvula de Purga do Canister}

A válvula de purga do canister mostrada na Figura 3 é o atuador do sistema que permite o aproveitamento dos gases presentes no tanque de combustível que iriam evaporar para a atmosfera piorando a situação do meio ambiente. Trata-se de um solenoide que interliga o filtro de carvão ativo do canister, ao coletor de admissão logo após ao corpo de borboleta do motor fazendo assim com que os gases sejam sugados e queimados pelo motor [5]. Sua localização varia de veículo para veículo.

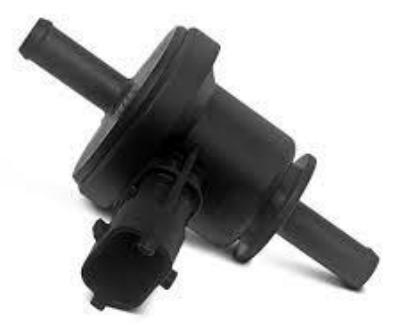

FigurA 3. Válvula de Purga do Canister (Autos.culturamix.com, 2018).

\subsubsection{Eletro Injetor}


Os eletros injetores conhecidos como "bicos injetores" são componentes de alta tecnologia comandados eletronicamente pelo módulo de injeção através de pulsos elétricos, fazendo com que ele abra e feche em frações de segundos pulverizando a quantidade certa de combustível dentro dos dutos do coletor de admissão. Estão localizados no coletor de admissão e são de fácil reconhecimento por serem todos semelhantes ao da Figura 4. Nos carros mais atuais esse componente atua diretamente na câmara de combustão, conhecido como sistema de injeção direta, onde há um maior aproveitamento do combustível [5].

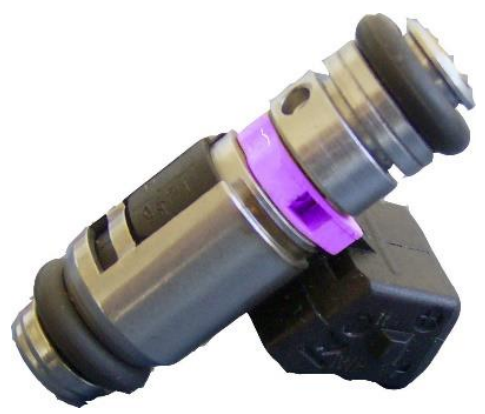

FIGURA 4. Eletro Injetor (Autoservico.blogspot.com, 2018).

\subsubsection{Eletro Ventilador}

Também conhecido como ventilador do radiador, mostrado na Figura 5, é responsável por forçar a troca de calor entre o radiador, onde contém o liquido de arrefecimento responsável por controlar a temperatura do motor, e o ambiente puxando o ar por dentro das aletas de alumínio do radiador. Trabalha em conjunto com o sensor de temperatura do motor que informará a ECU a temperatura do motor em tempo real. É facilmente encontrado na frente do veículo [5].

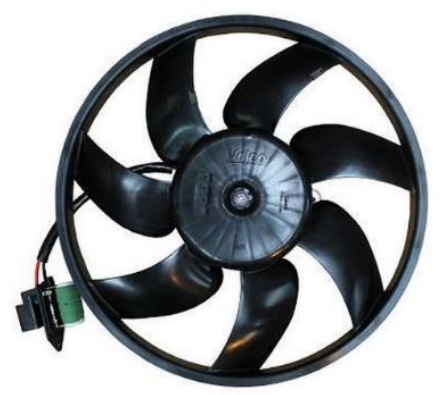

FIGURA 5. Eletro Ventilador (Canaldapeça.com, 2018).

\subsubsection{Bobina de Ignição}

A bobina de ignição é o componente que transforma a baixa tensão de $12 \mathrm{~V}$ da bateria do veículo em uma alta tensão que pode chegar a $30000 \mathrm{~V}$ através do enrolamento primário, que recebe os $12 \mathrm{~V}$ do sistema, e secundário, que envia a alta tensão para as velas, e manda através de cabos para a vela de ignição que iniciará a combustão por meio da centelha. São de fácil localização pois ficam próximas as velas e possuem características físicas comuns. Os sistemas antigos (ignição convencional) utilizam uma bobina e um distribuidor para distribuir a faísca a todos os cilindros. Nos sistemas intermediários é utilizada uma bobina eletrônica, como mostra a Figura 6.1, ligada diretamente a dois ou a quatro cilindros e nos veículos mais modernos aplica-se uma bobina por cilindro, conhecidas popularmente por bobinas "caneta", para melhor rendimento, conforme Figura 6.2 [5]. 


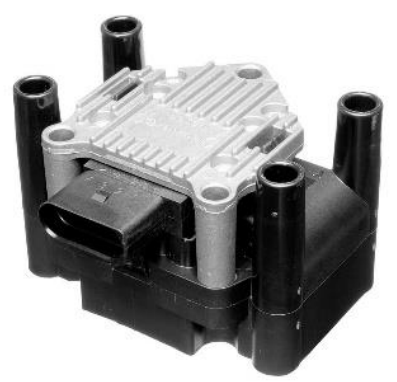

FIGURA 6.1. Bobina de quatro saídas (Canaldapeça.com, 2018).

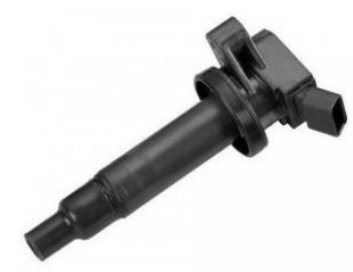

FIGURA 6.2. Bobina tipo “caneta” (jahuautopecas.com, 2018).

\subsubsection{Velas de Ignição}

A vela é um componente fabricado com um eletrodo central revestido de cerâmica isolante como mostra a Figura 7. É responsável por receber a alta corrente da bobina e transforma-la em centelha dentro da câmara de combustão fazendo com que ocorra a expansão dos gases promovendo o funcionamento do motor. São encontradas rosqueadas no cabeçote do motor sendo necessária uma ferramenta especifica para a sua remoção. Por ser necessária sua presença para que haja a combustão dentro da câmara de combustão o motor demanda uma vela para cada cilindro [6].

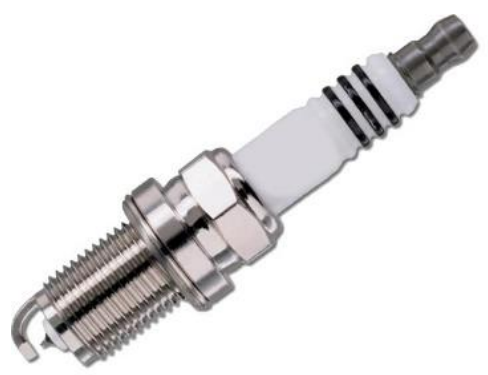

FIGURA 7. Vela de Ignição (Bermano.com, 2018).

\subsubsection{Bomba de Combustível}

A bomba de combustível mostrada na Figura 8 tem como função básica mandar o combustível pela linha principal do tanque até os bicos injetores sob alta pressão controlada. Como a demanda de combustível varia de acordo com a carga exigida pelo motor, o excesso de combustível retorna ao tanque pela linha de retorno. Ela fica localizada dentro do tanque de combustível geralmente em conjunto com o sensor de nível. Seu local de acesso é abaixo do banco inferior traseiro [5]. 


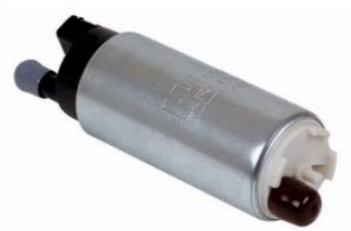

FIGURA 8. Bomba de Combustível (Autos.culturamix.com, 2018).

\subsection{Sensores}

\subsubsection{Sensor de Nível}

Localizado dentro do tanque de combustível do veículo o sensor de nível, mostrado na Figura 9, tem como função informar a ECU a quantidade de combustível presente no tanque bem como indicar ao motorista através do ponteiro no painel do veículo. No caso dos veículos bicombustíveis a ECU ao perceber que o nível no tanque subiu iniciará o monitoramento do sensor de oxigênio para que seja feito o reconhecimento da nova mistura de combustível [5].

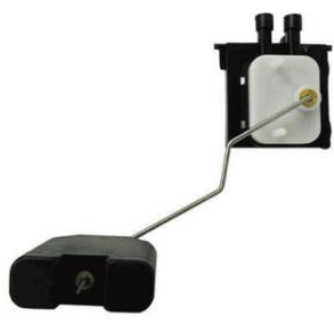

FIGURA 9. Sensor de Nível (Canaldapeçaweb.com, 2018).

\subsubsection{Sensor de Oxigênio}

É um dos componentes mais importantes do sistema criado com o intuito de informar o sistema a respeito da estequiometria da combustão dentro do motor, gerando menos resíduos de $\mathrm{CO} 2$, uma vez que a sociedade encontra-se em constante busca por soluções que poluam cada vez menos o meio ambiente [7]. O sensor de oxigênio, indicado na Figura 10, fica rosqueado no coletor de escape e é responsável por detectar a quantidade de oxigênio presente nos gases eliminados pelo motor. Uma vez que a proporção de oxigênio na atmosfera é de $21 \%$, o sensor trabalha continuamente comparando e informando a ECU essa porcentagem através de variações de tensão, sendo a proporção maior que $21 \%$ indicando que a mistura de ar combustível está pobre, ou seja, o tempo de injeção dos bicos precisam aumentar para que haja essa compensação, e se a proporção for menor que $21 \%$ indicando que a mistura está rica, ou seja, tem excesso de combustível e esse excesso está sendo eliminado juntamente com os gases [5]. Este componente só entra em pleno funcionamento quando atinge $300^{\circ} \mathrm{C}$ e para que isso ele conta com uma resistência interna para acelerar o processo de aquecimento.

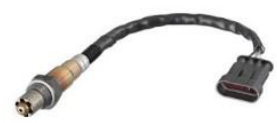

FIGURA 10. Sensor de Oxigênio (Canaldapeça.com, 2018).

\subsubsection{Sensor de Detonação}

O sensor de detonação, ilustrado na Figura 11, tem por função detectar as vibrações do bloco do motor originadas das explosões provenientes da câmara de combustão. Fica estrategicamente localizando no bloco de 
modo a captar a vibração de todos os cilindros. Atua informando a ECU quando ocorre cada explosão para que seja feita a correção do avanço do ângulo de ignição [8].

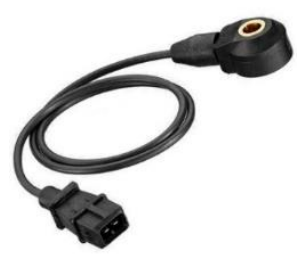

FIGURA 11. Sensor de Detonação (Autos.culturamix.com, 2018).

\subsubsection{Sensor de Rotação e Sensor de Fase}

O sensor de rotação, mostrado na Figura 12, trabalha em conjunto com uma peça chamada roda fônica que se localiza na parte inferior do motor, mas especificamente presa ao virabrequim [9]. Essa roda fônica contem 58 dentes igualmente espaçadas com uma falha que corresponde a dois dentes. Essa falha indica a posição angular do motor. O sensor de rotação é do tipo indutivo, ou seja, cada dente ao passar pelo sensor gera uma pequena corrente e a ECU trabalha exatamente com a ausência dessa corrente ao passar pela falha da roda fônica. Ao passar pela falha a ECU sabe exatamente qual a posição angular do motor para que faça a injeção de combustível de forma correta [5]. O sensor de fase trabalha de forma idêntica ao sensor de rotação necessitando também da roda fônica, diferenciando apenas na sua localização, o comando de válvulas.

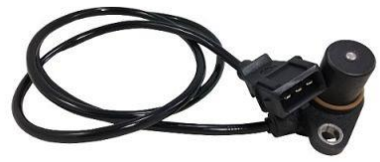

FIGURA 12. Sensor de rotação (Portalauto.com, 2018).

\subsubsection{Sensor de Temperatura do Motor}

Geralmente localizado no cabeçote do motor por ser a parte mais quente, o sensor de temperatura, ilustrado na Figura 13, tem como função informar a ECU a temperatura de trabalho do motor em tempo real. É um sensor do tipo resistivo, ou seja, ele varia sua resistência de acordo com a variação da temperatura do motor. Nas ocasiões de motor frio, geralmente pela manhã, a ECU aumenta o tempo de injeção afim de enriquecer a mistura para que o motor atinja mais rapidamente a temperatura ideal de trabalho [10].

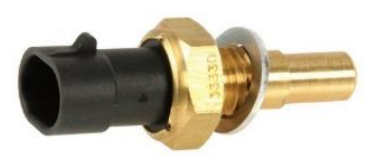

FIGURA 13. Sensor de Temperatura (Carrosinfoco.com, 2018).

\section{MATERIAIS E MÉTODOS}

Para o experimento prático e verificações dos parâmetros básicos de funcionamento, foi utilizado o multímetro da marca XT referência DT830B. De baixo custo e precisão de leitura de duas casas decimais, o multímetro, ilustrado na Figura 14, pode ser adquirido facilmente em lojas de eletrônicos e é feito para medições de grandezas elétricas como por exemplo resistências e tensão em corrente contínua e alternada. Composto geralmente por um botão seletor giratório, um mostrador que pode ser digital ou analógico e dois terminais de prova, um vermelho e um preto. As pontas de prova servem para interligar o equipamento com o componente 
a ser aferido. Na escala de corrente contínua existem as variações que aumentam ou diminuem a precisão da leitura contudo não deve ser selecionada uma escala menor do que a leitura que se espera obter correndo o risco de danificar o equipamento. Por exemplo, se é conhecido que o valor da tensão da bateria do veículo é de $12,6 \mathrm{~V}$ com o motor desligado deve ser feita a leitura na escala de $20 \mathrm{~V}$ para que a precisão do resultado seja alta porém se usada a escala de $200 \mathrm{~V}$ obtém-se o mesmo valor entretanto com a precisão mais baixa. O mesmo se aplica as escalas da função ohmímetro, sempre deve-se utilizar no equipamento o valor mais próximo acima do esperado na medição. Para os experimentos foi feito o uso do mesmo em funções e escalas diferentes.

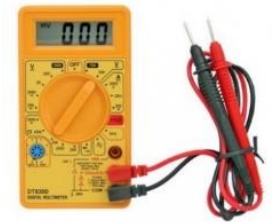

FIGURA 14. Multímetro Digital (Cemcables.com, 2018).

O veículo analisado foi o Corsa Sedan 1.4 Flex ano 2010 da General Motors (GM), e os parâmetros utilizados como referência foram para tal veículo obtidos no manual de manutenção do mesmo disponível na internet. Contudo a metodologia para obtenção dos dados é similar para os demais tipos de veículos, como também para outras montadoras, pois a base de funcionamento é a mesma, sendo necessária apenas a pesquisa dos novos parâmetros de referência que podem ser obtidos também na internet. Alguns componentes foram removidos do veículo para melhor visualização, mas podem ser realizados os testes com os mesmos no local.

\section{RESULTADOS E DISCUSSÕES}

Conhecendo o funcionamento geral do motor ciclo Otto, bem como a atuação e localização de cada componente básico da injeção eletrônica, este tópico abordará quais sintomas o veículo pode apresentar quando esses componentes entram em modo de falha e quais são os possíveis diagnósticos a serem realizados com o uso do multímetro, uma vez que a problemática do trabalho envolve diagnósticos precisos feitos por pessoas com baixo ou nenhum conhecimento na área e com equipamento de baixo custo e fácil acesso.

- Motor de Passo de Marcha Lenta: A falha neste componente causa oscilação na rotação do veículo em marcha lenta também indicada pela luz de anomalia do sistema de injeção. Este componente apresenta no geral quatro terminais. O teste, como mostra a Figura 15, foi feito com o componente na bancada e com o multímetro na função ohmímetro foi verificada uma resistência na faixa de 50 e $65 \Omega$ entre os pares de terminais das extremidades indicando funcionamento normal. Qualquer valor fora esse padrão indica falha no componente [11].

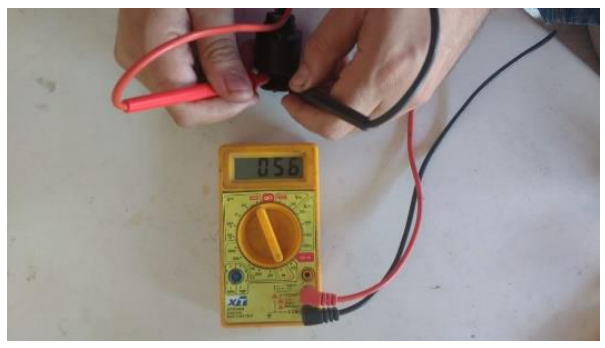

FigurA 15. Teste Motor de Passo (Autoria Própria, 2018).

- Válvula de Purga do Canister: Defeitos neste componente não apresentam sintomas perceptíveis ao motorista, porém acenderá a luz de anomalia do sistema de injeção [5]. O teste deste componente foi feito com um multímetro na função ohmímetro na escala de $200 \Omega$, como ilustra a Figura 16, verificando a resistência entre os únicos dois terminais da válvula, não sendo necessária sua remoção. O resultado foi de aproximadamente $25 \Omega$ que indica funcionamento normal. A ausência de resistência indicará uma possível falha no componente [11]. 


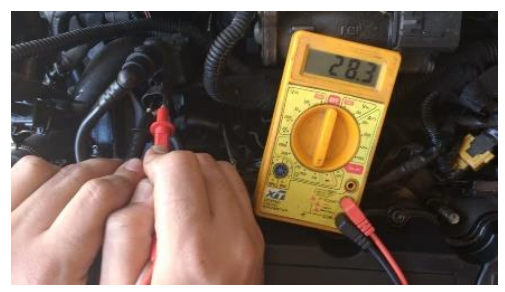

FIGURA 16. Teste da Válvula do Canister (Autoria Própria, 2018).

- Eletro Injetor: Quando apresenta falha na maioria das vezes o problema ocorre por obstrução da passagem do combustível por algum resíduo sólido que o filtro de combustível não reteve, porém foi possível verificar sua resistência para saber se o mesmo encontra-se queimado. Foi notado que existia resistência entre os únicos dois terminais do injetor, como mostra a Figura 17, verificado com multímetro na função ohmímetro na escala de $200 \Omega$. A ausência de resistência indicaria injetor danificado [11]. Para o teste de resistência não se faz necessária a remoção do componente.

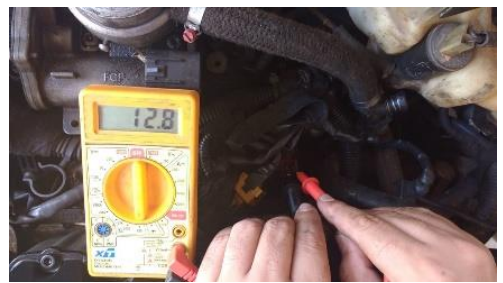

FIGURA 17. Teste do Injetor (Autoria Própria, 2018).

- Eletro Ventilador: Quando entra em modo de falha o motor superaquece e ele não é acionado. Este componente por conter vários modelos com quantidades de terminais que variam não foi possível um diagnóstico preciso com o multímetro.

- Bobina de Ignição: Com a falha deste componente o motor fica oscilando na marcha lenta, sem força, alto consumo de combustível ou em alguns casos o motor não entra em funcionamento. Para o teste do enrolamento primário foi realizada a leitura entre os pares de terminais das extremidades e para o secundário foi conectado as pontas de prova nas conexões dos cabos de vela. Fazendo o teste, com o componente apenas desconectado, usando um multímetro na função ohmímetro na escala $200 \Omega$, a leitura da resistência no primário ficou abaixo de $5 \Omega$, como mostra a Figura 18.1, que indica início de fadiga do componente e no secundário, usando a escala de $20 \mathrm{k}$ ficou entre 4 e $6 \mathrm{k} \Omega$, como mostra a Figura 18.2, considerado dentro do padrão de funcionamento [11].

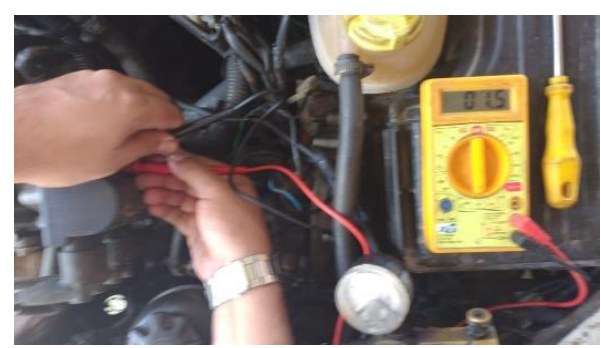

FiguRA 18.1. Teste do Primário (Autoria

Própria, 2018)

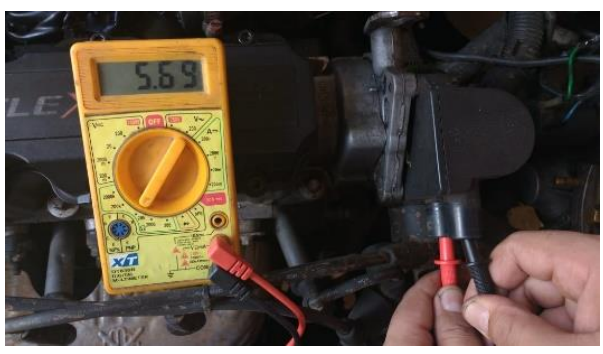

FIGURA 18.2. Teste do Secundário (Autoria

Própria, 2018)

- Velas de Ignição: Para a realização do teste foi preciso remover o componente do veículo. Para isso foi utilizada uma chave do tipo soquete $21 \mathrm{~mm}$ longo para a remoção e o multímetro na função ohmímetro na escala de $20 \mathrm{k}$ para o teste. Obteve-se uma leitura entre 3 e $7,5 \mathrm{k} \Omega$, parâmetro para esse modelo, para todas as velas, medidas estas feitas entre parte superior da vela e o eletrodo central na parte inferior, como mostra a Figura 19. Também se faz necessária a inspeção visual do componente notando que não apresentou rachaduras no revestimento cerâmico nem acumulo de resíduos da 
combustão ao redor do eletrodo central, o que indicaria sinal de fadiga ou aplicação incorreta do componente [11].

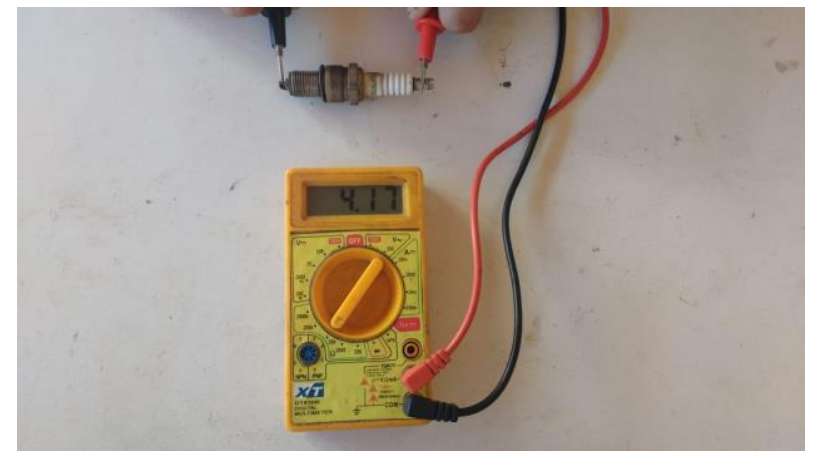

FIGURA 19. Teste da Vela (Autoria Própria, 2018).

- Bomba de Combustível: O teste de vazão da bomba só pode ser feito com o equipamento específico porém foi testada a resistência elétrica da bomba. Para o teste foi utilizado o multímetro na função de continuidade e verificou-se que não há continuidade entre os terminais da bomba, como mostra a Figura 20, indicando que o mesmo encontra-se queimado. Caso apresente continuidade a bomba estaria funcionando porém como dito deve-se verificar a pressão com o equipamento específico [11]. Este componente danificado apresenta falta de potência principalmente em altas rotações ou, no caso de queima, o não funcionamento do motor.

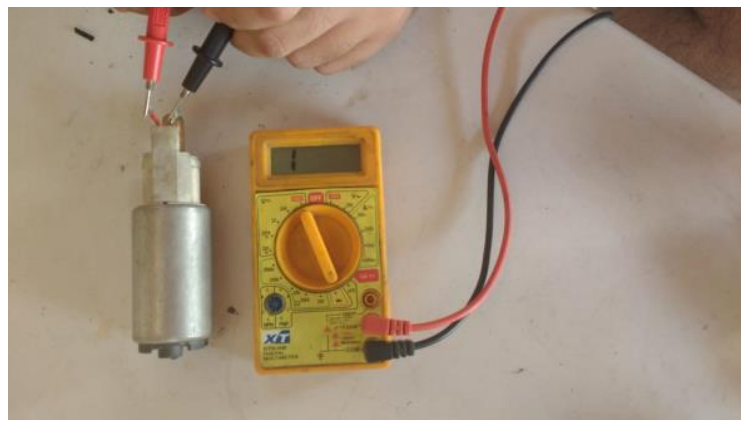

Figura 20. Teste da Bomba de Combustível (Autoria Própria, 2018).

- Sensor de nível: A falha neste componente apresentará uma leitura errada do nível de combustível presente no tanque do veículo porém não interfere diretamente no funcionamento do motor. No caso dos veículos equipados com computador de bordo haverá leituras erradas referente a $\mathrm{Km} / \mathrm{l}$ presente no tanque [5]. Para o teste foi necessária a remoção do componente de dentro do tanque e feita a leitura da resistência do sensor utilizando o multímetro na função ohmímetro na escala de $2000 \mathrm{k}$. A leitura foi de aproximadamente $40 \Omega$ com o sensor levantado, simulando tanque cheio, como ilustra a Figura 20.1, e aproximadamente $250 \Omega$ com o sensor totalmente abaixado, ilustrado na Figura 21.2, simulando tanque vazio, estando dentro dos padrões e indicando perfeito funcionamento. Valores distantes do padrão de 40 e $250 \Omega$ indicam falha no componente. Este sensor conta com apenas dois terminais [11]. 


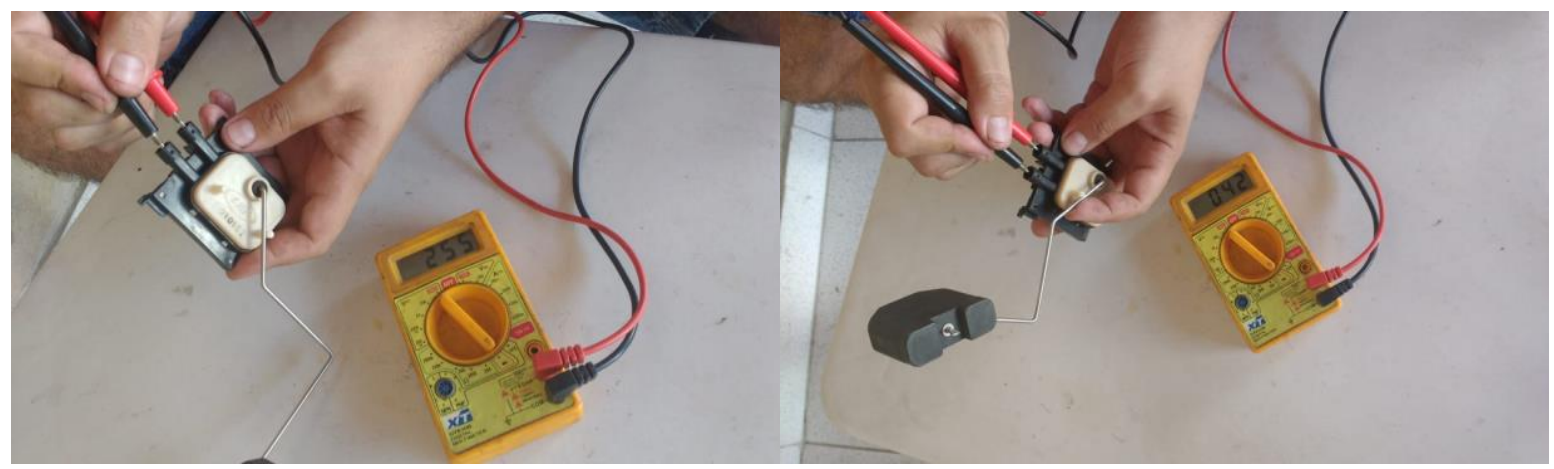

FIGURA 21.1. Teste no Nível Mínimo (Autoria

Própria, 2018).
FIGURA 21.2. Teste no Nível Máximo (Autoria

Própria, 2018).

- Sensor de Oxigênio: Principal característica do veículo quando este componente apresenta falha é o alto consumo de combustível associado ao odor característico exalado pelo escapamento. O mesmo possui um conector com 4 terminais onde os dois brancos são da resistência de aquecimento, o cinza para aterramento e o preto que envia o sinal para a ECU. Usando um multímetro na função ohmímetro na escala de $200 \Omega$, foi verificado que existe resistência, como mostra a Figura 22, indicando que a função aquecimento funciona corretamente. Para a medida da variação de tensão é necessário está com o motor em funcionamento e conectar as pontas de prova do multímetro, na função Corrente Contínua (CC) e escala de $20 \mathrm{~V}$, nos terminais dos fios cinza e preto. A variação de tensão que deverá ser visualizada no multímetro deve ser entre 0,03 e $0,95 \mathrm{~V}$ oscilando constantemente. Valores fora desse padrão ou com pouca oscilação indicam que o sensor não está mais funcionando de forma eficiente, deixando sempre a mistura pobre ou rica [11].

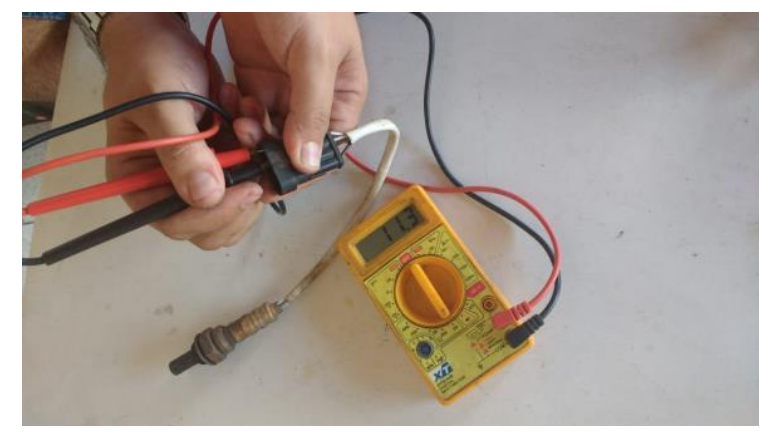

FIGURA 22. Teste da Resistência de Aquecimento (Autoria Própria, 2018).

- Sensor de Detonação: A falha deste componente faz com que a ECU limite o giro do motor a aproximadamente 3000rpm. Para o teste é preciso a retirada do componente e utilizado o multímetro na função Corrente Contínua (CC) na escala de $20 \mathrm{~V}$. Com cada ponta de prova do multímetro em cada um dos terminais do sensor, que deve ser fixado firmemente com a mão na bancada, aplica-se pequenas batidas na mesa próximo ao sensor. Deve-se notar a variação da corrente indicando que o componente está em perfeito funcionamento. Caso não seja detectada variação na corrente o sensor está defeituoso [11].

- Sensor de Rotação: Quando este componente falha o principal sintoma é o não funcionamento do motor associada à luz de anomalia do sistema no painel. Para a realização do teste não é preciso a remoção do componente basta identificar a extremidade do chicote. Por se tratar de um sensor do tipo indutivo, foi utilizado o multímetro na função corrente alternada (CA) na escala de $200 \mathrm{~V}$. Desconectando o chicote e conectando as pontas de prova do multímetro nos terminais central e da direita foi dada a partida no motor e foi notada a geração de picos de tensão de $0,4 \mathrm{~V}$, como mostra a Figura 23, indicando o correto funcionamento do sensor. Caso isso não ocorresse seria necessário 
refazer o teste analisando com as pontas de prova no terminal central e esquerdo. A não geração de sinal em ambos os testes indicaria falha no componente [11].

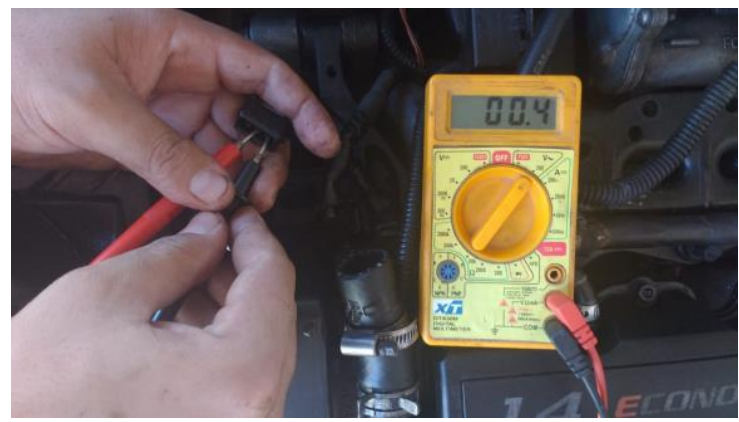

FIGURA 23. Teste do Sensor de Rotação (Autoria Própria, 2018).

- Sensor de Temperatura: A falha deste componente está associada leitura incorreta da temperatura no painel do veículo bem como o eletro ventilador sempre ligado e o não funcionamento do ar condicionado, nos veículos mais recentes. Para o teste foi utilizado o multímetro na função ohmímetro na escala de 20k. O teste foi realizado com o componente na bancada para melhor visualização porém pode ser realizando com o mesmo no local. Com as pontas de prova conectadas a cada terminal do sensor foi obtido o valor de $1,99 \mathrm{k} \Omega$, como mostra a Figura 24, que indica funcionamento inicial regular. Com o componente instalado e o motor iniciando o funcionamento com a temperatura fria foi possível acompanhar o decréscimo dessa resistência para o valor de aproximadamente $140 \Omega$ com o acionamento do eletro ventilador, que também indica funcionamento regular. Para sensores mais antigos com apenas um terminal repete-se o teste com uma ponta de prova no terminal do sensor e outra na lataria do veículo. A não presença de resistência indica falha no componente [11].

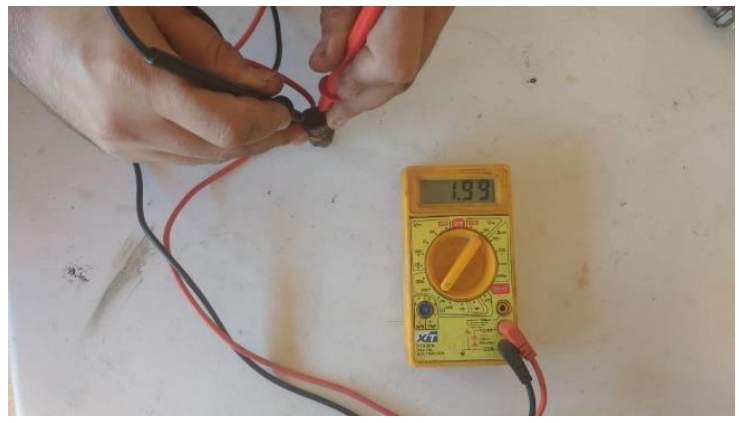

FIGURA 24. Teste do Sensor de Temperatura (Autoria Própria, 2018).

A ECU por se tratar de um componente eletrônico não pode ser testado com o multímetro entretanto raramente ele entra em modo de falha pois é fabricado com componentes de alta durabilidade. Existem outros testes básicos que podem ser realizados com o multímetro como por exemplo a verificação do nível de tensão da bateria e o diagnóstico do funcionamento básico do alternador, componente responsável por recarregar a bateria e manter o sistema alimentado durante o funcionamento do motor. $\mathrm{O}$ teste de tensão da bateria consiste em, com o motor desligado, conectar o multímetro na função Corrente Continua (CC) e na escala de $20 \mathrm{~V}$ nos polos da bateria, empregando a ponta de prova vermelha no polo positivo e a ponta de prova preta no polo negativo da bateria. A leitura não deve ser inferior a 11,8V, que indicaria bateria descarregada ou fadigada. Para o teste básico do alternador deve-se realizar o mesmo procedimento porém com o motor em funcionamento. Se a leitura for inferior a 13,5V indica que o alternador está com problema ou o sistema está sobrecarregado. Uma leitura excelente deve ser em torno de $14,4 \mathrm{~V}$. 


\section{CONCLUSÃO}

Realizadas as medições nos componentes considerados neste trabalho, foi percebido o quão simples é a metodologia para realização destas. De certa forma, isso converge com o objetivo de incentivar aos proprietários dos automóveis, mesmo sem uma especialização na área, a realização do diagnóstico simplificado e eficiente no seu próprio carro, cabendo a este documento o papel de orientá-los e sanar suas dúvidas. Percebeu-se também o amplo uso do multímetro, equipamento de tão fácil acesso e baixo custo, geralmente associado à atividades específicas do contexto de instalações elétricas industriais e residenciais, que realiza medições reais com alto grau de fidelidade na proposta deste trabalho. Foi notado ainda, que apesar do amplo leque de opções que o multímetro oferece nem todos os componentes podem ser testados com o mesmo, havendo a necessidade de uma análise especializada. Contudo a grande maioria dos componentes básicos oferecem suporte para o uso desta ferramenta. Abaixo, na Tabela 1, temos todos os parâmetros e resultados obtidos nos testes de cada componente bem como a conclusão de funcionamento dos mesmos.

TABela 1. Parâmetros e Valores (Autoria Própria).

\begin{tabular}{cccc}
\hline Componente & Parâmetros & Valores Obtidos & Conclusão \\
\hline Motor de Passo & 50 a $65 \Omega$ & $56 \Omega$ & OK \\
\hline Válvula do Canister & Próximos de $25 \Omega$ & $28,3 \Omega$ & OK \\
\hline Eletro Injetor & Presença de Resistência & $12,8 \Omega$ & OK \\
Pobina de Ignição & primário e de 4 a $6 \mathrm{k} \Omega$ & $1,5 \Omega$ para primário e & OK \\
& para secundário & $5,69 \Omega$ para secundário & \\
\hline Velas de Ignição & 3 a $7,5 \mathrm{k} \Omega$ & OK \\
\hline Bomba de Combustível & Presença de Resistência & Sem Resistência & Danificada \\
\hline Sensor de Nível & $40 \Omega$ no Nível Mínimo e & $42 \Omega$ no Nível Mínimo e & OK \\
\hline Sensor de Oxigênio & Presença de Resistência & $11,3 \Omega$ & OK \\
\hline Sensor de Rotação & Presença de Tensão & $0,4 \mathrm{~V}$ & OK \\
\hline Sensor de Temperatura & $25 \mathrm{k} \Omega$ frio e $140 \Omega$ Quente & $1,99 \mathrm{k} \Omega$ Frio e $140 \Omega$ & OK \\
\hline
\end{tabular}

\section{REFERÊNCIAS}

[1] ROCHA NETO, Osvaldo Assis. Mobilidade urbana e cultural do automóvel na singularidade da metrópole modernista brasileira. 2012.

[2] A HISTÓRIA dos Motores a Combustão Interna. 2017. Disponível em: <https://autocarup.com.br/historiamotor-a-combustao/>. Acesso em: 10 ago. 2018.

[3] OLIVEIRA, Carlos Alexandre de; ROSA, Andrea da. Motores de Combustão Interna: Álcool e Gasolina. Santa Maria: Senai-RS, 2003.

[4] COMO surgiu a injeção eletrônica? 2015. Disponível em: <http://revista.socarrao.com.br/nosocarrao/historia-socarrao-antigo/como-surgiu-a-injecao-eletronica/>. Acesso em: 21 ago. 2018.

[5] LOURENÇO, Igo Bittencourt; SILVA FILHO, João Batista da; F. JUNIOR, Jose Carlos

Gonçalves. Sistema de Alimentação Flexível. 2009. 63 f. Monografia (Especialização) - Curso de Tecnologia em Manutenção Industrial, Instituto Federal de Educação, Ciência e Tecnologia Fluminense, Campos dos Goytacazes, 2009.

[6] VELAS de Ignição: (quando trocar). (quando trocar). 2014. Disponível em:

<http://www.bermano.com.br/blog/tag/como-limpar-as-velas-de-ignicao/>. Acesso em: 21 ago. 2018.

[7] CRUZ, César Roberto. Desempenho de Sondas Lambda no Monitoramento de Motores do Ciclo Otto

Alimentados Por Etanol e GNV. 2015. 109 f. Dissertação (Mestrado) - Curso de Pós Graduação em

Engenharia Mecânica, Unesp, Bauru, 2015.

[8] O QUE é Sensor de Detonação. 2013. Disponível em: <http://autos.culturamix.com/mecanica/o-que-e-

R4EM, v.1, n.1, p. 73-86, 2019 
sensor-de-detonacao>. Acesso em: 21 ago. 2018.

[9] O QUE é e como funciona o Sensor de Rotação. 2018. Disponível em:

<https://portalauto.com.br/manutencao/sensor-de-rotacao/>. Acesso em: 21 ago. 2018.

[10] INJEÇÃO Eletrônica: Por Dentro do Sensor de Temperatura do Motor. Por Dentro do Sensor de Temperatura do Motor. 2012. Disponível em: <http://www.carrosinfoco.com.br/carros/2012/07/injecaoeletronica-por-dentro-do-sensor-de-temperatura-do-motor/>. Acesso em: 21 ago. 2018.

[11] SIMPLO AUTOMOTIVO. Version 2011/1. Caxias do Sul - RS: Rene Gobbi, 2011. 1 CD-ROM. 